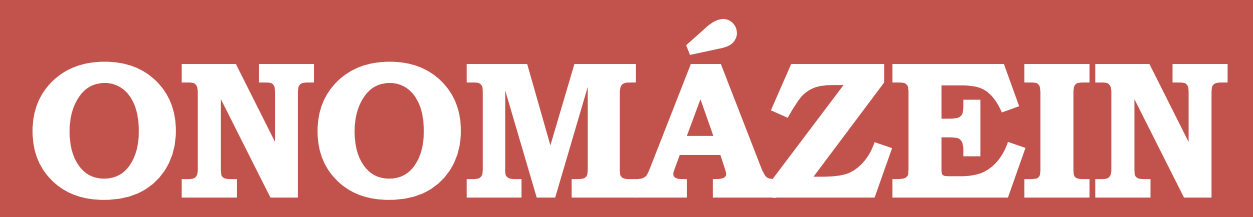

Journal of linguistics, philology and translation

\title{
The role of creativity on the \\ translation of motion verbs: data on the translation product and process
}

\author{
Ana Rojo López \\ Universidad de Murcia \\ España
}

\section{Paula Cifuentes Férez \\ Universidad de Murcia \\ España}

\section{Marina Ramos Caro \\ Universidad de Murcia \\ España}

\section{(c) $($ ii) $\ominus$}

Ana Rojo López: Departamento de Traducción e Interpretación, Facultad de Letras, Universidad de Murcia, España. | E-mail: anarojo@um.es

Paula Cifuentes Férez: Departamento de Traducción e Interpretación, Facultad de Letras, Universidad de Murcia, España. | E-mail: paulacf@um.es

Marina Ramos Caro: Departamento de Traducción e Interpretación, Facultad de Letras, Universidad de Murcia, España. | E-mail:marinaramos@um.es 


\section{Abstract}

The present study researches the correlation between translators' creative personality and their behaviour by using a combination of psychological, key-logging and screen-recording methods as well as the evaluation of participants' translation output. Participants were asked to translate a literary text without knowing that it posed the additional challenge of transferring manner of motion verbs into Spanish. The experiment correlated the participants' scores on a validated creativity test (i.e., CREA, Corbalán Berná et al., 2003) with their scores on process indicators of fluency as one of the key dimensions of creativity as well as product indicators of flexibility, novelty, and accuracy. To this purpose, the logging tool Inputlog was used to measure dwell ratio, total translation time, time interval between ST processing and TT production and time devoted to revision. The screen recording software CamStudio was also used to analyse participants' creativity in searching and retrieving information. Although few significant statistical results were found, our study suggests that creative translators' potential can be traced both in their translation product and process.

Keywords: creativity; translation; motion; process; product. 


\section{Introduction}

By the end of the 2oth century, acknowledgment of translation as a problem-solving activity points to the need to define the processes and strategies associated with translational creativity. Moreover, the view that translation problems inherently require a great deal of creativity contributes not only to expanding creativity research to typically process-related areas, such as the exploration of translation process phases or the development of translation competence, but also to developing new cognitive methods to research the process (e.g., think aloud protocols or TAPs, key-logging, etc.).

To date, Bayer-Hohenwarter $(2009,2010,2011,2013)$ has provided the most detailed and extensive method to measure creativity in translation by combining both product- and process-based methods of analysis. And yet, Bayer-Hohenwarter's assessment model still makes no attempt to measure the impact of creativity as a translator's personality trait. In the present study, we analyse the influence of translators' creative potential on both the product and process of the translation of a literary text highly rich in manner of motion descriptions, a highly demanding challenge which might benefit from creative problem-solving.

The present paper is thus the first attempt to measure the correlation between translators' creative potential and their behaviour. In order to do so, we firstly build our theoretical framework on the concept of creativity and its relation to translation (section 2.1), focusing specifically on the translation of motion verbs, a special challenge for translators which might benefit from a creative problem-solving potential (section 2.2). Secondly, the design and methods used in our experiments are described in section 3 . Then, section 4 introduces the results and discussion of the two studies conducted to measure the influence of creativity on the translation process (4.1.) and product (4.2). Lastly, section 5 offers an overview of both experiments and some closing remarks for our study.

\section{Theoretical framework}

\subsection{Creativity and translation}

In Western society, creativity is a highly valued attribute which, in the last decades, has become a key focus of attention. However, research on creativity has been fragmented due to lack of consensus about its definition and measurement. In psychology, from the early classical models of creative problem-solving (Wallas, 1926; Shaw, 1989) to the latest evidences in cognitive psychology and neuroscience, creativity has proven to be a complex construct involving the interplay of several activities, such as the interaction between pre- and non-verbal processes, feelings of the 'self' and the alternation of focused and defocused states of attention (Aldous, 2007). 
Creativity is also a highly valued competence for translators, since translation is widely conceived as a problem-solving activity that requires creative professionals. In translation studies, creativity was first analysed by focusing on the product, most specifically on three factors relating to the creative rendering of target texts (TT, hereafter): the presence of textual markers of creativity, and the novelty and adequacy of translations (Rojo López, 2017). One of the most common methods for researching creativity in translation has zeroed in on analysing optional shifts as markers of creative behaviour (e.g., work on literary (Perteghella \& Loffredo, 2006), advertising (Valdés, 2008) and legal translation (Šarčević, 2000)). But this type of analysis only provides indirect inference on what is going on in the translators' minds, which reinforces the need for closer exploration of the translation process.

With the development of new cognitive methods to research the process, creativity started to be experimentally explored by means of different methods and techniques, such as TAPs (Hubscher-Davidson, 2005, 2006; Cho, 2006; Kußmaul, 2005, 2007; Audet, 2008) and key-logging (Heiden, 2005; Bayer-Hohenwarter, 2009, 2010, 2011, 2013). Most of these studies combined the use of product- and process-based methods; for instance, Kußmaul (1991) developed the first typology of cognitive shifts and used TAPS to prove that the strategies of brainstorming and visualization are useful to promote creativity in the translation classroom.

A cognitive process tightly connected to creativity and highly relevant to translation is information processing speed. In Cognitive Translation Studies, noteworthy work can be found on the analysis of information processing speed (e.g., Muñoz Martín \& Martín de León, 2018; Muñoz Martín \& Cardona Guerra, 2018), but very rarely in connection to creative processes. One exception is the work by Heiden (2005), who used key-logging records to analyse creative processes in translation and found that longer revision periods are a strong indicator of creative problem-solving processes.

Although the impact of the translator's creative potential on information processing speed has not yet been researched - at least to our knowledge-in translation studies, intriguing evidence is now available from psychology. Vartanian et al. (2007), for instance, explored the correlations between participants' creative potential and their reaction time when performing a series of tasks. Their results reported negative correlations on tasks that did not involve interference (Hick Task, Concept Verification Task), but positive correlations on tasks requiring the participants' inhibition of interfering information (Negative Priming, Global Precedence). They interpreted these results as evidence that the relation between creative potential and reaction time is a function of differential focusing of attention. Participants with higher creative potential scored higher on tasks that allow them to narrow their focus of attention, but lower on tasks allowing them to widen this, such as those tasks where global features must be inhibited in favour of local ones.

But despite stimulating evidence from related areas, the most comprehensive attempt to measure creativity in both the translation process and product is still the work by Bayer-Ho- 
henwarter (2009, 2010, 2011). One of her basic premises is that creative processes are found when translators deviate from a mere reproduction of the source text (ST, hereafter), whereas non-creative processes essentially consist of reproducing the ST unit (Bayer-Hohenwarter, 2009: 46). She bases her framework on Guilford's (1950) nine dimensions of creativity and proposes the following four dimensions: flexibility, which is reflected in the use of translation shifts - here understood as cognitive operations; novelty, interpreted as the presence of unique solutions; acceptability, reflected in the absence of errors; and fluency, reflected in routine or automatic behaviour. The first three dimensions can be observed and assessed in the translation product, whereas the last one is accessed by examining the translation process.

As far as flexibility is concerned, Bayer-Hohenwarter (2009, 2010, 2011) distinguishes between primary shifts and secondary shifts. In very general terms, primary shifts involve semantic changes in the level of abstraction. They include three main types: abstraction, concretization and modification. Abstraction refers to cases where translators resort to solutions that are more general or abstract than ST meaning; concretization involves expressing the ST idea in greater detail; and modification refers to the use of a level of abstraction similar to that of the ST. Secondary changes are optional and include four types: explanation, i.e., making information contained in the ST explicit; emphatization, in which a new value is added by including a novel element; change of perspective, which incorporates traditional modulation and/or transposition; and enrichment, which adds a metaphor or any other original contribution to meaning.

In Bayer-Hohenwarter's model (2009, 2010, 2011), creativity on the process is mainly measured by zeroing in on fluency, i.e., the ability to create different translation solutions in a rapid and routinized way. She specifically measures four parameters of fluency: dedication ratio, total translation time, automaticity and spontaneity. Dedication ratio is described as the time a translator devotes to a translation unit in relation to their total translation time. Total translation time is also measured to analyze translators' creative behavior, since Bayer-Hohenwarter (2009, 2010, 2011) considers that long translation times are indicators of non-routinized processes, whereas short translation times point to routine behavior. Measures of automaticity must meet all of the following conditions: firstly, automaticity is regarded to take place when a translator needs less than three seconds to start writing the TT (Krings, 1986: 137); secondly, the first translation output is considered to be the final solution for a certain translation unit; and thirdly, the TAP shows no comment made by the translator on this translation unit (Bayer-Hohenwarter, 2009, 2010, 2011). Finally, there are also cases when the translation process cannot be considered automatic, but can still be considered spontaneous. Measures of spontaneity include situations in which the translator is not able to solve a problem in the first place, but manages to find a satisfactory solution after some mental reorganization. Spontaneity is considered to take place even when the particular problem is commented aloud on the TAP, but still must meet the condition of taking less than three seconds after re-reading the ST. 
Bayer-Hohenwarter's (2011) work suggests that successful translation performance is not necessarily defined by a high proportion of creative shifts, but by "reflected decisions on the use of reproductions versus creative shifts depending on the specific demands of a particular translation unit" (p. 686). In other words, successful translators are those who achieve a cognitively efficient balance between flexible problem solving and routinized reflex (Bayer-Hohenwarter, 2010). But as thorough as her comprehensive assessment model is, it still makes no attempt to analyse the effects that creative personality might have on both the translation process and product. For this reason, the present paper explores the role that translators' creativity potential might play on both the translation process and product. The translation of motion verbs is chosen as a challenge that may benefit from creative problem-solving strategies.

\subsection{The challenge of translating motion verbs}

Nowadays, it is a well-established fact that languages carve reality in different ways when it comes to express motion events (Berman \& Slobin, 1994; Strömqvist \& Verhoeven, 2004; Talmy, 1985). These differences pose great challenges for translators, especially when dealing with typologically different languages, categorised either as verb-framed or satellite-framed (e.g., Slobin, 1991, 1996a, 1966b; Ibarretxe-Antuñano \& Filipović, 2013; Alonso, 2016, 2018; Rojo López \& Cifuentes-Férez, 2017; Cifuentes-Férez \& Molés-Cases, 2020). Talmy’s (1985, 1991, 2000) now familiar distinction proposes that the two types of languages differ with regard to which morphosyntactic element - the verb or the satellite-typically encodes the Path or trajectory of motion in a motion event ${ }^{1}$. In a verb-framed language such as Spanish, Path is usually expressed by the main verb (e.g., salir 'exit', entrar 'enter', subir 'ascend', bajar 'descend', cruzar 'cross') while Manner and Cause are often relegated to a separate constituent such as a gerund (e.g., corriendo 'running') or a prepositional or an adverbial phrase (e.g., muy rápido 'very quickly'). In satellite-framed languages such as English, Path is expressed by satellites (e.g., go down/up/into) or prepositional phrases (e.g., into/out of the room), while Manner or Cause are encoded in the main verb (e.g., tiptoe, wander, stroll, dash, soar, waddle). Moreover, it has also been attested that Spanish, as a verb-framed language, only licenses the use of manner verbs when the motion event depicted is atelic, in other words, when the motion event is an activity with duration and no boundary-crossing is predicated (i.e., into, out of), and when describing fast downward motion, such as tirarse a la piscina (lit. to throw oneself into the pool).

1 According to Talmy (2000: 25): "The basic Motion event consists of one object (the Figure) moving or located with respect to another object (the reference object or Ground). It is analyzed as having four components: besides Figure and Ground, there are Path and Motion. The Path (with capital P) is the path followed or site occupied by the Figure object with respect to the Ground object. The component of Motion (with capital M) refers to the presence per se of motion or locatedness in the event [...]. In addition to these internal components, a Motion event can be associated with an external Co-event that most often bears the relation of Manner [i.e., the way the Figures moves] or of Cause [i.e., the reason that makes the Figure move] to it". 
Besides problems caused by these typological differences, translators must also face challenges derived by differences between English and Spanish in the nature of their manner of motion verb lexicon. To this respect, Slobin $(1997,2006)$ and Cifuentes-Férez (2010)_among other scholars-have noticed that in the English motion verb lexicon, manner is more elaborated in terms of the fine grained information expressed, and the use and number of manner verbs is much greater than in Spanish, which causes additional difficulties when it comes to translate those specific manner verbs. Let us consider, for example, the translation of the English verb "to scramble" in example (1) below:

1) English ST: [...] the three of them scrambled through it [the door].

2) Spanish TT: [...] los tres se metieron por ella [la puerta].

Lit. The three put themselves in through it.

In this example, "to scramble" denotes that the characters move quickly in an unorderly manner, which cannot be fully rendered into Spanish for two reasons: firstly, in Spanish it is compulsory to express that the main figures in the event go through a door (i.e., boundary-crossing constraint) and, secondly, there is not a Spanish manner verb encoding the very same information expressed in "to scramble". As a result, the translator opted for using a path verb to express the boundary-crossing, and omitted the manner information, even if some could have been rendered it outside the verb phrase (e.g., desordenadamente 'unorderly').

A theory that has proven fruitful for exploring how the differing attention paid to manner of motion may have consequences for translation is Slobin's (1996b, 2003, 2006) thinking-for-translating hypothesis. Results from his work have shown that in English-to-Spanish translation, manner information is commonly omitted and path information is changed or reduced, whereas in Spanish-to-English translation, path information is usually kept, and Manner is also kept and even added to the TT. By way of illustration, consider these examples taken from Slobin (1997: 443):

3) English ST: He strolled across the room to the door.

4) Spanish TT: Se dirigió a la puerta.

Lit. (He) directed himself to the door

In example (3), two trajectories or paths are described (across $X$ to $Y$ ), whereas in (4) the across $X$ is omitted as it can be easily inferred that if the figure is already in the room, in order to reach for the door, he needs to walk across the room. Moreover, the manner information encoded in the verb "to stroll" (i.e., to walk in a leisurely manner) has also been omitted in the Spanish translation with the verb dirigirse (lit. to head to). This line of research pioneered by Slobin and followed up by many scholars (e.g., Ibarretxe-Antuñano, 2003; Filipović, 2007, 2008; Ibarretxe-Antuñano \& Filipović, 2013; Cifuentes-Férez, 2013; Cifuentes-Férez \& Rojo 
López, 2015; Molés-Cases, 2016; Lewandowski \& Mateu, 2016) shows that translators adapt the ST to the rhetorical style of the target audience, creating a text which sounds natural for their target readers.

Within the wealth of studies on the translation of motion events, three main areas of research can be distinguished, namely, the use of translation as a method for assessing the acquisition of the L2 lexicalization pattern for describing motion events (e.g., Cerda, 2010; Alonso, 2011, 2016; De Knop \& Gallez, 2011; Cifuentes-Férez, 2015); descriptive studies on the strategies and techniques used when translating motion events between and among typologically different or similar languages (e.g., Ibarretxe-Antuñano, 2003; Cifuentes-Férez, 2013; Cifuentes-Férez \& Rojo López, 2015; Lewandowski \& Mateu, 2016; Molés-Cases, 2016); and reception studies on the impact that Manner loss may have on the target audience (e.g., Filipović, 2011; Rojo López \& Cifuentes-Férez, 2017; Cifuentes-Férez, 2018).

In the first area of research (i.e., the use of translation as a way for measuring acquisition of foreign language patterns for expressing motion events), results have revealed that LI motion lexicalization patterns interfere with the production of target-like motion constructions, and that language proficiency does not seem to be a good predictor for a native-like use of motion lexicalization patterns. For these reasons, scholars working on this field advocate for incorporating formal instruction on typological differences in the lexicalization of motion into the classroom and curricula.

Regarding studies on the strategies used when translating motion events, a number of relevant translation strategies has been identified by different scholars drawing from Slobin's work (for a detailed overview, see Ibarretxe-Antuñano \& Filipović (2013: 265-266)). More recent research, such as that by Molés-Cases $(2016,2018)$, has proposed seven translation strategies based on those used in descriptive translation studies (namely, lexical equivalence, paraphrase or explanation, reduction, specification, modulation, omission, and addition). Needless to say, no matter which set of strategies scholars use for their analysis or the labels they are given, they reflect the final decisions (i.e., on the translation product) that translators take after mulling over their choices (i.e., throughout the translation process). These strategies can be equated with both primary and secondary creative shifts, as discussed in the previous section. Thus, we can observe that primary creative shift-abstraction would be found in the case of the reduction translation technique; primary creative shift-concretization is related to the specification technique; the secondary creative shift-explanation can be equated with paraphrase or explanation; the secondary creative shift-change of perspective with modulation technique, etc.

Finally, concerning the impact of the degree of inclusion of Manner on the reception of the translation product, results from research have shown that - at least when dealing with the translation of violent events - the more manner information is contained in the TT, the more likely the event is to be judged as more violent, since linguistic framing does have a crucial 
role in how people interpret events. Much in the same line of these findings, when interpreters perceive more violence in the events depicted by using manner verbs, they seem to be more prone to include manner information (cf. Cifuentes-Férez, 2018).

Notwithstanding the bulk of research, no attention has been paid so far to the role of translators' personality, such as their creative potential, when it comes to addressing the well-known problem of translating manner verbs from English into Spanish. Thus, the question that arises at this point is whether translators' creative personality may be related to the degree of inclusion of manner information when translating narrative texts highly rich in motion events. To address this issue, the following section introduces two studies designed to measure the correlation between translators' creative intelligence and their behaviour when dealing with the translation of motion events in an excerpt of Mockingjay by Suzanne Collins (2008).

\section{The studies}

The two studies were designed to explore the relationship between translators' creative potential and their behaviour when translating motion verbs. They shared the same experimental setting, but differed in materials and research objects: Study 1 focused on the analysis of textual indicators of creative behaviour; Study 2 zeroed in on the translation process by using a combination of psychological and key-logging methods. Thus, results from the studies are not comparable.

\subsection{Aims and hypotheses}

Study 1 aimed at analysing the participants' rendering of complex motion events by examining the relations between their creativity potential and their scores on indicators of flexibility and novelty as two of the key dimensions of creativity, as well as on overall TT accuracy (namely, transfer of meaning, pragmatic function, and correctness in terms of grammatical aspects, punctuation, etc.). Drawing on the literature review, three hypotheses were postulated. Firstly, a positive correlation was assumed between participants' creative potential and their use of creative shifts, as we expected more creative participants to use a higher number of creative shifts. Secondly, a positive correlation was also predicted between participants' creativity and their degree of novel or unique solutions. And thirdly, a negative correlation was expected between participants' creativity and their number of accuracy mistakes, assuming that the higher their creativity scores, the less mistakes they would make.

The aim of Study 2 was to investigate the relationship between creativity and speed of translation processing by testing correlations between participants' creative potential and measures of process indicators of fluency as one of the key dimensions of creativity. On the basis of psychological results, two hypotheses were postulated in this experiment: firstly, participants with higher creative potential were hypothesized to display longer translation times 
and a higher number of pauses than those with lower creative potential, since translation is assumed to be a complex task involving the participants' widening of their focus of attention. Secondly, despite being generally slower, those participants with higher creative potential were expected to be faster than those with lower creative potential in finding a solution for the problem demanding a more creative solution.

\subsection{Participants}

31 second-year and 36 final-year students from the Translation and Interpreting Degree at the University of Murcia took part in the first experiment. This sample consisted of a total of 67 students whose mother tongue was Spanish and their second language was English. There were 56 females and 11 males, and their age ranged from 21 to 29 years (mean 23.3). They were given course credit for their participation.

Since Study 2 required a highly complex analysis of the data (see section 4.2), 20 students were selected at random from the group of final-year participants. There were 4 males and 16 females and their age ranged from 21 to 29 years (mean 24.1).

\subsection{Task and materials}

Participants were asked to translate into Spanish a text of 174 words from the novel Mockingjay by Suzanne Collins (2008), which is part of The Hunger Games saga (see Appendix 1).

In Study 1, two sentences of similar length (40 characters) were selected as potential translation challenges because of the complexity of manner information conveyed in the motion events depicted:

- Unit 1: I zigzag and dive and leap to avoid the fireballs.

- Unit 2: I twist and scuttle backward on my hands and feet.

Since the aims and hypotheses of Study 2 involved comparing the participants' behaviour when dealing with creative vs. routine units, two different types of translation challenges were selected: one demanding a more creative, non-literal solution-unit 2 in the first studyand one allowing for a more routine, literal rendering. Both units were also of similar length:

- Creative unit: I twist and scuttle backward on my hands and feet (40 characters).

- Routine unit: The fireball crashes into the ground at my side (39 characters).

\subsection{Procedure}

The experiment was performed in a university computer room, where the logging tool Input$\log$ 7.0.0.11 (Leijten \& Van Wees, 2013) had been previously installed in every computer. Firstly, 
participants signed a consent form and were requested to complete a psychological profile test: the Spanish Creative Intelligence Test - CREA (Corbalán Berná et al., 2003, see Appendix 2). To complete the test, participants were asked to formulate as many questions as possible within a 4-minute time period. Then, they received specific instructions on the computer programmes and windows they needed to open and on how to write and save their translation. Participants were not informed of the real aim of the experiment until they finished.

In Study 1 , the translations of the selected units were assessed both for the accuracy and creativity of the solutions (see Correction Sheet in Appendix 3). For accuracy, points were subtracted out of a total score of 10 points for mistakes in rendering the meaning, in achieving the pragmatic function, and for grammatical and spelling mistakes (what we called correctness). In contrast, for creativity, points were awarded for indicators of both flexibility (i.e., use of creative shifts: primary and secondary) and novelty (i.e., unique solutions). Novelty was actually assessed by considering all the solutions provided by the sample of participants and awarding those which are unique, i.e., used in less than $10 \%$ or $50 \%$ of the cases (see Appendix 3 ).

\subsection{Analysis of results}

To facilitate the interpretation of results, data from the two studies are introduced in two separate sections: results from the study focusing on the translation product (3.5.1) and those from the process-oriented analysis (3.5.2).

\subsubsection{Study 1. Product-oriented analysis of results}

Since creativity and accuracy scores did not display a normal distribution, Spearman's rho correlations were conducted. In what follows, results are introduced and discussed for each of the hypotheses posed in Study 1.

\subsubsection{Hypothesis 1}

Our first hypothesis predicted that student translators with higher creativity scores on the CREA test will use more primary and secondary translation shifts than those with lower scores. As displayed in Table 1 , regarding primary shifts, significant positive correlations were only found between the participants' creativity scores and their use of modification $\left(r_{s}=.354, p<.05\right)$ and of concretization $\left(r_{s}=.446, p<.001\right)$. Enrichment as a type of secondary shift was also significantly correlated with the participants' creativity scores $\left(r_{s}=.449, p<.001\right)$. Moreover, as Table 1 shows, the total number of primary shifts and of secondary shifts also yielded highly significant positive correlations (Primary shifts: $r_{s}=.491, p<.001$; Secondary shifts: $r_{s}=.449, p<.001$ ).

Our data show that student translators with greater levels of creative intelligence have resorted more often to the use of concretization, modification, and enrichment shifts. When rendering the manner information contained in the ST, creative students tend to provide 


\section{TABLE 1}

Correlations between creative intelligence scores (CREA) and creative shifts ${ }^{2}$

\begin{tabular}{lcc} 
& SPEARMAN RHO & P-VALUE \\
Primary shift - Abstraction & -.081 & .513 \\
\hline Primary shift - Modification & & $.003^{*}$ \\
\hline Primary shift - Concretization & .354 & $.000^{*}$ \\
\hline Total of primary shifts & .446 & $.000^{*}$ \\
\hline Secondary shift - Explication & .491 & - \\
\hline Secondary shift - Emphasizing & - & - \\
\hline Secondary shift - Change of perspective & - & - \\
\hline Secondary shift - Enrichment & .450 & $.000^{*}$ \\
\hline Total of secondary shifts & .449 & $.000^{*}$ \\
\hline
\end{tabular}

more specific manner information (i.e., concretization) in the TT (e.g., translating zigzag as correr en zigzag 'lit. to run in zigzag'; scuttle as escabullirse 'to slink away'), modify the manner information contained in the ST (e.g., translating zigzag as esquivar 'to dodge, to avoid', dive as saltar 'to jump', lanzarse as 'to throw oneself'), and use the English lexicalization pattern when it is allowed in Spanish (i.e., enrichment) (e.g., translating "I zigzag and dive and leap to avoid the fireballs" as zigzagueo, me lanzo y salto para esquivar las bolas de fuego (lit. "I zigzag, throw myself, and jump to avoid the fireballs'). Since the use of these translation shifts allowed students to include more manner information in the TTs, data point to the effort of more creative students to maintain or reproduce manner information.

\subsubsection{Hypothesis 2}

The second hypothesis predicted a positive correlation between the participants' creativity scores and the novelty of their solutions. However, as shown in Table 2, no significant correlations were found between the participants' scores on the CREA test and their use of unique, novel solutions for the two creative units.

A plausible explanation for the lack of statistically significant results may be the low potential of the selected challenges for creativity. After all, when translating manner verbs, the

2 Please note that no Spearman's rho and p-value are displayed for Explication, Emphasizing, and Change of perspective shifts as only a couple of instances of all these secondary shifts were found in the total sample of student translators. 


\section{TABLE 2}

Correlations between creative intelligence scores (CREA) and novelty

\begin{tabular}{lcc} 
& SPEARMAN RHO & P-VALUE \\
Novelty translation unit 1 & -.630 & .180 \\
\hline Novelty translation unit 2 & -.193 & .429 \\
\hline Total novelty & -.065 & .580 \\
\hline
\end{tabular}

originality of the solutions seems to be mostly restricted to the selection of unique lexical items and/or the attempt to transfer the highest degree of manner information. Moreover, this assumption agrees with previous results on the lack of correlations between students' creativity scores and the novelty of their solutions when translating routine units with low potential for creativity (Rojo López, 2019).

\subsubsection{Hypothesis 3}

Our third hypothesis predicted a negative correlation between creativity scores and number of mistakes or errors in the ST, that is, it was predicted that the higher the creativity scores on the CREA test, the less number of errors were to be found in the TT. However, as can be observed in Table 3, no significant correlations were obtained between creativity scores and TT in terms of meaning, pragmatic function, and correctness.

\section{TABLE 3}

Correlations between creative intelligence scores (CREA) and accuracy in the TT

\begin{tabular}{lcc} 
& SPEARMAN RHO & P-VALUE \\
Accuracy in meaning & .150 & .207 \\
\hline Accuracy in pragmatics & -.111 & .353 \\
\hline Accuracy in correctness & -.165 & .167 \\
\hline Total accuracy & .084 & .486 \\
\hline
\end{tabular}

This finding is in line with claims on the lack of conclusive evidence for a positive effect of creativity on TT accuracy (Rojo López, 2017). Student translators with higher creative potential do not necessarily make less errors in the TT. As argued by Bayer-Hohenwarter (2010, 2011), successful translation performance does not appear to depend on the use of a high proportion of creative shifts, but on a balance between knowing when to be creative and when to translate more literally. 


\subsubsection{Study 2. Process-oriented analysis of results}

In Study 2, data on the participants' translation process were collected by using Inputlog, a key-logging programme that allowed us to analyse their behaviour on different aspects of the process.

\subsubsection{Hypothesis 1}

Our first hypothesis predicted that participants with higher creative potential would display longer translation times and a higher number of pauses than those with lower creative potential.

Information on participants' time and pause behaviour was obtained by analysing the following aspects of their writing process with the different functions available in Inputlog:

A. Total translation time. Data on the overall duration of the translation task were obtained from the function of Summary analysis.

B. Total time devoted to the revision phase. Data on the amount of time that participants devoted to revise their translation were obtained from the function Revision analysis.

C. Total time spent on documentation. Data on the total time that participants used to get documented or search for relevant information were obtained from the function of Source analysis.

D. Total time spent on the ST (D.1) and TT (D.2). Data were obtained from the function of Source analysis.

E. Total time devoted to the drafting stage. Information on this aspect was calculated by subtracting the time spent with revision (parameter B), documentation (parameter $\mathrm{C}$ ), and ST (parameter D.1) from the total time of the whole process (parameter A).

F. Total number of pauses. Data on the number of pauses were obtained from the function of Pause analysis. The set value for the minimum problem-solving pause was calculated by multiplying our participants' median of pauses between words by 2 (Rosenqvist, 2015). Traditionally in TPR, pauses have been considered to point to problem-solving activities when they last longer than 3 seconds, but more recent studies (Muñoz Martín \& Martín de León, 2018) point to the importance of using more accurate and flexible measurement of the pauses depending on the performance of each individual translator. Based on Rosenqvist' work on writing process research (2015), Muñoz Martín \& Martín de León (2018) establish 2 thresholds for each participant. Each participant's low threshold is calculated by multiplying the median pause within words by 1.5 and the high threshold by multiplying the median pause within words by 3 . They then use these relative measures to categorize participants' measurement of short pauses (between 200 ms. and low threshold), mid pauses (between low and high 
threshold) and long pauses (above high threshold). In a recent study, Muñoz Martín \& Cardona Guerra (2018) prove that this method is more accurate, since long pauses are able to capture more problems than standard 3-second pauses.

\subsubsection{Hypothesis 2}

Our second hypothesis predicted that participants with higher creative potential would be more efficient, i.e., faster, in finding a solution for the problems that demanded a more creative solution.

To test this hypothesis parameters related to the creative and routine units were obtained by combining the functions of General and Linear analyses. We located all the actions performed on each of these two units, keeping in mind that one participant could have been focused on the same unit at different times of the process. Consequently, we scanned the entire document in order to locate all actions dedicated to each unit. The following parameters were analysed:

G. Time devoted to the creative unit.

H. Time dedication to the routine unit.

I. Number of pauses in each of the two units.

Since data did not show a normal distribution, a Mann-Whitney Test was used to compare differences between participants with low and high creativity. The participants' mean scores on the CREA test were used to classify them above (high) or below (low) the mean, as shown in Table 4 :

\section{TABLE 4}

Time and pauses vs. CREA

\begin{tabular}{|c|c|c|c|c|c|c|}
\hline & $\begin{array}{l}\text { CREA_MEAN } \\
(\text { MEAN }=11)\end{array}$ & $\mathbf{N}$ & MEAN & $\begin{array}{l}\text { STANDARD } \\
\text { DEVIATION }\end{array}$ & $\begin{array}{l}\text { STANDARD } \\
\text { ERROR OF } \\
\text { THE MEAN }\end{array}$ & P-VALUE \\
\hline \multirow{2}{*}{$\begin{array}{l}\text { TOTAL } \\
\text { TRANSLATION TIME }\end{array}$} & Low & 10 & 1639.80 & 426.01 & 134.71 & \multirow{2}{*}{.112} \\
\hline & High & 10 & 1968.20 & 378.69 & 119.75 & \\
\hline \multirow{2}{*}{$\begin{array}{l}\text { TOTAL NUMBER } \\
\text { OF PAUSES }\end{array}$} & Low & 10 & 189.70 & 70.72 & 22.36 & \multirow{2}{*}{.212} \\
\hline & High & 10 & 218.60 & 51.21 & 16.20 & \\
\hline \multirow{2}{*}{$\begin{array}{l}\text { TIME DEVOTED } \\
\text { TO PAUSES }\end{array}$} & LoW & 10 & 493.97 & 292.22 & 92.41 & \multirow{2}{*}{.096} \\
\hline & High & 10 & 716.62 & 270.37 & 85.50 & \\
\hline
\end{tabular}

As can be seen in Table 4, statistically significant differences were not reported for any of the parameters tested. Nevertheless, mean values point to some interesting tendencies, as the fact that participants with the highest creativity scores took more time to finish the whole task, pausing more often and longer. 
In order to level out individual variations in speed and increase comparability, all data were then relativised with reference to each participant's total translation time and number of pauses, as shown in Table 5 below:

\section{TABLE 5}

Time and pauses (relative values) vs. CREA

\begin{tabular}{|c|c|c|c|c|c|}
\hline & $\begin{array}{l}\text { CREA_MEAN } \\
(M E A N=11)\end{array}$ & $\mathbf{N}$ & MEAN & $\begin{array}{l}\text { STANDARD } \\
\text { DEVIATION }\end{array}$ & P-VALUE* \\
\hline \multirow{2}{*}{ REVISION TIME } & Low & 10 & .58 & .146 & \multirow{2}{*}{.753} \\
\hline & High & 10 & .56 & .130 & \\
\hline \multirow{2}{*}{ DOCUMENTATION TIME } & Low & 10 & .27 & .075 & \multirow{2}{*}{.536} \\
\hline & High & 10 & .29 & .065 & \\
\hline \multirow{2}{*}{ SOURCE TEXT TIME } & Low & 10 & .08 & .136 & \multirow{2}{*}{.894} \\
\hline & High & 10 & .05 & .045 & \\
\hline \multirow{2}{*}{ TARGET TEXT TIME } & Low & 10 & .57 & .190 & \multirow{2}{*}{.724} \\
\hline & High & 10 & .52 & .202 & \\
\hline \multirow{2}{*}{$\begin{array}{l}\text { TIME DEVOTED TO } \\
\text { TT WRITING }\end{array}$} & Low & 10 & .35 & .162 & \multirow{2}{*}{.616} \\
\hline & High & 10 & .38 & .126 & \\
\hline \multirow{2}{*}{ TIME ON CREATIVE UNIT } & Low & 10 & .09 & .083 & \multirow{2}{*}{.650} \\
\hline & High & 10 & .06 & .037 & \\
\hline \multirow{2}{*}{ TIME ON ROUTINE UNIT } & Low & 10 & .02 & .012 & \multirow{2}{*}{.762} \\
\hline & High & 10 & .02 & .008 & \\
\hline \multirow{2}{*}{$\begin{array}{l}\text { TIME DEVOTED } \\
\text { TO PAUSES }\end{array}$} & Low & 10 & .34 & .097 & \multirow{2}{*}{.698} \\
\hline & High & 10 & .36 & .093 & \\
\hline \multirow{2}{*}{$\begin{array}{l}\text { NUMBER OF PAUSES } \\
\text { CREATIVE UNIT }\end{array}$} & Low & 10 & .05 & .032 & \multirow{2}{*}{.354} \\
\hline & High & 10 & .05 & .033 & \\
\hline \multirow{2}{*}{$\begin{array}{l}\text { NUMBER OF PAUSES } \\
\text { ROUTINE UNIT }\end{array}$} & Low & 10 & .02 & .010 & \multirow{2}{*}{.324} \\
\hline & High & 10 & .01 & .007 & \\
\hline
\end{tabular}

*Mann-Whitney

As shown in Table 5, all participants spent longer on the TT over the ST (TT mean 0.5 for low creative participants, 0.52 for high creative participants; ST mean 0.08 for low creative participants, 0.05 for high creative participants). They also spent longer revising it than consulting documentation sources (revision mean: 0.58 for low creative participants, 0.56 for high creative participants; documentation mean: 0.27 for low creative participants, 0.29 for high creative participants). They all spent longer and paused more often on the creative unit than the 
routine one (CU mean: 0.09 for low creative participants, 0.06 for high creative participants; RU mean: 0.02 for all participants).

Concerning differences between participants with high and low creativity, those with the highest creativity scores devoted more time to documentation than less creative participants (HC: 0.29; LC: 0.27), but took less time revising the translation (HC: 0.56; LC: 0.58). More creative participants also devoted slightly less time to both the ST and TT than less creative participants (ST: 0.05 vs. 0.08; TT: 0.052 vs. 0.057), and spent less time on the target text overall (HC: 0.52; LC: 0.57). Interestingly, they spent longer writing the target text than participants with low creativity potential (HC: 0.38; LC: 0.35).

As already indicated, all participants spent longer on the creative unit than the routine one. But participants with higher creativity took less time than those with lower creative potential in translating both the creative and the routine problem, since the time difference between both problems was smaller for participants with higher creativity (HC: .048; LC: .077) (see Table 6):

\section{TABLE 6}

Differences in time and number of pauses between Creative - Routine units vs. CREA

\begin{tabular}{lccccc} 
& & N & MEAN & $\begin{array}{c}\text { STANDARD } \\
\text { DEVIATION }\end{array}$ & P-VALUE* \\
\cline { 2 - 4 } $\begin{array}{l}\text { Time difference Creative } \\
\text { - Routine units }\end{array}$ & Low & 10 & .077341 & .0856882 & 0.796 \\
\cline { 2 - 5 } $\begin{array}{l}\text { Pause difference Creative } \\
\text { - Routine units }\end{array}$ & High & 10 & .048770 & .0390613 & 0.481 \\
\cline { 2 - 5 } & High & 10 & 8.000000 & 6.8799225 & \\
\hline
\end{tabular}

*Mann-Whitney

As reported with time, more pauses were found in the creative unit than in the routine one. As shown in Table 5, in general, participants with higher creativity scores devoted more time to pausing (HC: 36; LC: 34), but while they showed a similar number of pauses on the creative unit (HC: .05; LC: .05), they paused slightly less often than less creative participants in the routine unit (HC: .01; LC: .02). Table 6 shows that the difference between both problems in the number of pauses was bigger in the case of participants with higher creative potential (HC: 8.0; LC: 7.5), since they paused less than participants with lower creativity in the routine problem.

In fact, as shown in Tables 7 and 8 below, all participants took longer and paused more often translating the creative problem than the routine one (time CU: 0.08; RU: 0.02; pauses CU: 10.95; RU: 3.20), and the time and pause differences between both problems were statistically significant. These results can also serve as evidence for the difference established between both problems in terms of the type of solution demanded (i.e. creative vs. routine): 


\section{TABLE 7}

Time Routine vs. Creative units. Wilcoxon Signed-Rank Test

\begin{tabular}{lccccc} 
& MEAN & N & $\begin{array}{c}\text { STANDARD } \\
\text { DEVIATION }\end{array}$ & $\begin{array}{c}\text { STANDARD ERROR } \\
\text { OF THE MEAN }\end{array}$ & P-VALUE \\
\cline { 1 - 5 } TIME CREATIVE UNIT & .08 & 20 & .0646461 & .0144553 & \multirow{2}{*}{0.001} \\
\cline { 1 - 5 } TIME ROUTINE UNIT & .02 & 20 & .0102869 & .0023002 & \\
\hline
\end{tabular}

\section{TABLE 8}

Pauses Routine vs. Creative. Wilcoxon Signed-Rank Tes

\begin{tabular}{|c|c|c|c|c|c|}
\hline & MEAN & $\mathbf{N}$ & $\begin{array}{l}\text { STANDARD } \\
\text { DEVIATION }\end{array}$ & $\begin{array}{l}\text { STANDARD ERROR } \\
\text { OF THE MEAN }\end{array}$ & P-VALUE \\
\hline $\begin{array}{l}\text { NUMBER OF PAUSES } \\
\text { CREATIVE UNIT }\end{array}$ & 10.95 & 20 & 8.29378 & 1.85455 & \multirow{2}{*}{$<0.001$} \\
\hline $\begin{array}{l}\text { NUMBER OF PAUSES } \\
\text { ROUTINE UNIT }\end{array}$ & 3.20 & 20 & 1.82382 & .40782 & \\
\hline
\end{tabular}

In fact, even if no statistically significant correlation was found between the CREA scores and time devoted to pauses, the tendency of higher creativity participants to spend more time pausing can be shown in Figure 1 :

\section{FIGURE 1}

Relation between creativity scores and time spent on pauses

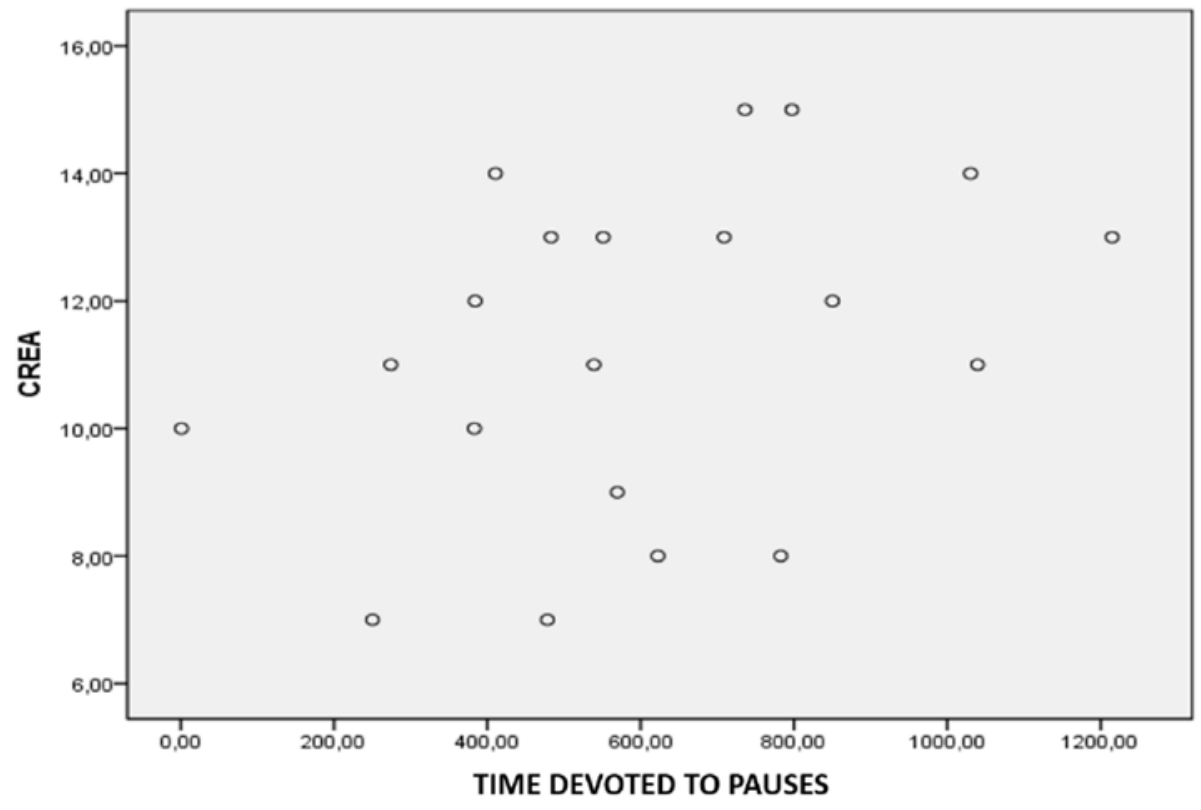




\section{Final discussion and conclusions}

Our first study reveals that student translators with higher creative potential resort more often to the use of creative shifts, favouring the inclusion of more manner information in the TT. However, no relation has been found among their levels of creative intelligence and the novelty or originality of their solutions, or between their creative intelligence scores and TT accuracy, suggesting that creative potential might not always lead to novel solutions or higher translation quality. This finding might be related to the results from Bayer-Hohenwarter (2010, 2011), which indicate that successful translation performance does not appear to depend on the use of a high proportion of creative shifts, but on a balance between knowing when to be creative and when to translate more literally.

In our second study no statistically significant results were found, but there are intriguing trends that seem to support our initial predictions and are, thus, worth exploring further: firstly, participants with higher creative potential generally took longer to complete the translation task than participants with lower creative potential. Even if no straight comparison can be established, this could be related to the result from Study a suggesting that students with higher creative potential use a greater number of translation shifts, being consequently slower. Moreover, from a process perspective, a plausible explanation from the lack of results in Study 1 relating to the relationship between creative intelligence and TT novelty or accuracy could be found in the complexity of translation as a task that does not allow participants to easily narrow their attention. Rather, the translation process demands a continuous inhibition and selection of information that is more likely to call for widening of attention. Psychological evidence shows that individuals' narrowing or widening of attention depends on the nature of the task performed and that widened apertures increase response time (cf. Oakley, 1996: 41-2).

More creative participants tended to devote more of their time to documentation and less to revision than less creative ones. More creative participants kept consulting documentation sources for the creative unit even at other points in their translation, probably in an attempt to connect different concepts and come up with a new solution. This sort of behaviour could also be interpreted as an example of the less ordered and structured thinking of more creative people (Vohs et al., 2013). Regarding their shorter revision times, they could mean that either they were generally faster and more efficient revisers (Hayes, 1989: 142), or that they did it less thoroughly because they tend to be more disorganized and careless (Torrance, 1962; Davis, 1989).

Interestingly, participants with lower creativity potential devoted more time to both ST and TT, while more creative participants spent more time writing or producing the TT. Low creative participants seemed to take longer reading and processing the ST, whereas high creative ones read it quicker and move on to other tasks (e.g., documentation, writing of the target text). 
Besides, when participants with high creativity potential were on the TT, they spent more time writing, displaying greater fluidity than low creative participants. Since most of the decision-making process takes place while producing the TT, this result suggests that more creative individuals may be faster when generating possible solutions or answers to a problem (a characteristic process of divergent thinking) (cf. Guilford, 1967).

Despite being generally slower, participants with higher creative potential were, however, faster than those with lower creative potential in finding a solution for the unit demanding a more creative solution. This result seems consistent with psychological evidence suggesting that creative people's performance is mostly enhanced when they face a creative challenge or when they are explicitly instructed to be original (Martindale \& Hasenfus, 1978). It is also coherent with evidence showing that gifted and creative individuals show higher alpha power levels than less creative ones (Jausovec, 2000). Even if, as repeatedly pointed out, no direct comparison can be established with Study 1 , this result is extremely interesting in the light of data from Study 1 , since participants with greater creative potential could be faster despite using a greater number of creative shifts.

Participants with higher creative potential spent more time pausing than those with less creative potential. But while they also seemed to pause more often when translating the creative unit, they paused less than participants with lower creative potential in translating the routine unit. On the one hand, the fact that they displayed longer pausing time suggests that more creative participants generally tend to devote more time to evaluate and weigh different solutions. On the other, evidence on their greater number of pauses in the creative unit versus the smaller number of pauses in the routine one could be interpreted as an indicator of their greater use of creative pauses, that is, of self-imposed, deliberate pauses taken to reflect on multiple solutions to a problem.

Overall, and despite the lack of consistent results, we have seen that creative translators' behaviour can be traced both in the translation product and process: we have found that creative translators do indeed produce more creative shifts than non-creative individuals in the TT, although their solutions might not be the most accurate or novel. This result is directly related to some of the tendencies we have observed in the analysis of the translation process: although highly creative individuals tend to be faster in finding a solution for the highly demanding creative units, they also seem to devote less time to revising and more to other tasks, such as pausing or to the documentation phase, and they tend to have a less structured translational behaviour.

But of course there are some limitations that might have led to the absence of conclusive results, our first drawback being derived from the use of only one test (CREA test) as predictor of creative intelligence as well as from the marking method. Although the CREA test is validated and has been successfully used in different areas, it is possible that it does not measure 
verbal aspects that may be essential in translation. For future research, other tests such as the Alternate Uses Test (Wallach \& Kogan, 1965) and the Creative Personality Scale (Gough, 1979) could be used. It could be the case that some tests are more suitable for measuring different dimensions of creativity (i.e., flexibility, novelty, etc.) in the translation product. Secondly, the marking method could also be affecting results, since problems were continuously reported to decide on the type of shift involved, especially for secondary creative shifts. One way to solve this limitation is to revise and refine the marking method. Moreover, for further research, it would be interesting to measure creativity in the product by comparing creative challenges with routine ones, since it could be plausible that creative intelligence might have a differing impact on the use of creative shifts and novelty in different types of translation units. Our experiment on the process also presents some clear limitations, the first being the sample size. The use of a single text might have also limited our results, and thus it would be highly advisable to replicate the study with a larger sample, even comparing contrastive profiles such as students vs. professionals, as well as different types of texts (technical, economic, informative, literary).

The influence of creative personality on translation combining both process and product analyses is certainly a significant step towards a better and deeper comprehension of the role of creativity in translation. The present paper is only a modest attempt to point to some existing trends and open further avenues for research. However, the type of triangulation work proposed here is needed to advance our knowledge of how cognitive abilities and even personality traits may be used to translators' best advantage at the different stages of the translation process in order to ensure a high-quality product.

\section{References}

Aldous, Carol, 2007: "Creativity, problem solving and innovative science: Insights from history, cognitive psychology and neuroscience", International Education Journal 8 (2), 176-186.

Alonso Alonso, Rosa, 2011: "The translation of Motion events from Spanish into English: a cross-linguistic perspective", Perspectives: Studies in Translatology 19 (4), 353-366.

Alonso Alonso, Rosa, 2016: "Cross-linguistic influence in the interpretation of boundary-crossing events in L2 acquisition”, Review of Cognitive Linguistics 14 (1), 161-182.

Alonso Alonso, Rosa, 2018: "Translating motion events into typologically distinct languages", Perspectives: Studies in Translatology 26 (3), 357-376.

Audet, Louis, 2008: "Évaluation de la traduction littéraire: de la «sensibilité à la littérarité» à la «littérarité en traduction»", TTR 2 (1), 127-172 [doi: 10.7202/029689ar]. 
Bayer-Hohenwarter, Gerrit, 2009: "Translational creativity: how to measure the unmeasurable" in Susanne Göpferich, Arnt Lykke Jakobsen \& Inger M. Mees (eds.): Behind the Mind: Methods, Models and Results in Translation Process Research. Copenhagen Studies in Language, vol. 37, Copenhagen: Samfundslitteratur, 39-59.

BAYER-Hohenwarter, Gerrit, 2010: "Comparing translational creativity scores of students and professionals: flexible problem-solving and/or fluent routine behaviour?” in Susanne GöPfERICH, Fabio Alves \& Inger M. Mees (eds.): New Approaches in Translation Process Research. Copenhagen Studies in Language, vol. 39, Copenhagen: Samfundslitteratur, 83-111.

Bayer-Hohenwarter, Gerrit, 2011: "Creative Shifts as a Means of Measuring and Promoting Creativity", Meta 56 (3), 663-692 [doi: 10.7202/1008339ar].

Bayer-Hohenwarter, Gerrit, 2013: "Triangulating translational creativity scores: A methodological study in translation process research" in Catherine Way, Sonia VandePItTE, Reine MeYLAerts \& Magdalena Bartlomiedjczyk (eds.): Tracks and Treks in Translation Studies, Amsterdam and Philadelphia: John Benjamins, 63-86.

Berman, Ruth, \& Dan I. SLobin, 1994: Relating events in narrative: A crosslinguistic developmental study, Hillsdale, Nueva Jersey: Lawrence Erlbaum Associates.

Cerda, Juan P., 2010: Estrategias utilizadas en la traducción inversa español-inglés de verbos de movimiento: un estudio en lingüística cognitiva. MA thesis, Universidad de Concepción, chile.

CHo, Sang-Eun, 2006: "Translator's Creativity found in the Process of Japanese-Korean Translation", Meta 51 (2), 378-388 [doi: 10.7202/013263ar].

Cifuentes-Férez, Paula, 2010: "The semantics of the English and the Spanish motion verb lexicons", Review of Cognitive Linguistics 8 (2), 233-271.

Cifuentes-Férez, 2013: “El Tratamiento de los Verbos de Manera de Movimiento y de los Caminos en la Traducción Inglés-Español de Textos Narrativos”, Miscelánea 47, 53-80.

Cifuentes-Férez, Paula, 2015: "Thinking-for-translating: acquisition of English physical motion constructions by Spanish translators in training", Cognitive Linguistics Studies 2 (2), 303-330.

Cifuentes-FÉrez, Paula, 2018: "Metodologías de investigación en movimiento y traducción” in AnA Rojo (ed.): La investigación en traducción: aspectos metodológicos y aplicaciones didácticas, Barcelona: Anthropos, 31-67. 
Cifuentes-Férez, Paula, \& Teresa Molés-Cases, 2020: "On the translation of boundary-crossing events: Evidence from an experiment with German and Spanish translation students", Vigo International Journal of Applied Linguistics 17, 87-111.

Cifuentes-Férez, Paula, \& Ana Rojo López, 2015: "Thinking for translating: A think-aloud protocol on the translation of manner-of-motion verbs", Target 27 (2), 273-300.

Corbalan Berna, Javier, Fermín Martínez Zaragoza, Danilo S. Donolo, Carlos Alonso Monreal, María Tejerina Arreal, \& Rosa María Limiñana Gras, 2003: CREA. Inteligencia Creativa. Una medida cognitiva de la creatividad, Madrid: TEA Ediciones.

Davis, Gary A., 1989: "Testing for creative potential", Contemporary Educational Psychology $14,257-274$.

De Knop, Sabine, \& Françoise Gallez, 2011: "Manner of motion: A privileged dimension of German expressions", International Journal of Cognitive Linguistics 2 (1), 25-40.

FILIPović, Luna, 2007: Talking about Motion: A Crosslinguistic Investigation of Lexicalization Patterns, Amsterdam: John Benjamins.

FILIPović, Luna, 2008: "Typology in action: Applying typological insights in the study of translation", International Journal of Applied Linguistics 18 (1), 23-40.

FILIPović, Luna, 2011: "Language as a witness: Insights from cognitive linguistics”, Speech, Language and the Law 14 (2), 245-267.

Gough, Harrison G., 1979: "A creative personality scale for the Adjective Check List", Journal of Personality and Social Psychology 37 (8), 1398-1405.

Gullford, Joy Paul, 1950: “Creativity”, American Psychologist 5, 444-454.

GuILford, Joy Paul, 1967: The Nature of Human Intelligence, New York: MacGraw-Hill.

HAyes, John R., 1989: "Cognitive Processes in Creativity" in John A. Glover, Royce R. Ronning, \& Cecil Reynolds (eds.): The Handbook of Creativity, New York: Springer Science and Business Media, 135-146.

Heiden, Tanja, 2005: "Blick in die Black Box: Kreative Momente im Übersetzungsprozess: eine experimentelle Studie mit Translog”, Meta 50 (2), 448-472 [doi: 10.7202/010993ar].

Hubscher-Davidson, Severine, 2005: "Psycholinguistic Similarities and Differences between Subjects as Seen through TAPS", International Journal of Translation 17 (12), 97-107. 
Hubscher-Davidson, Severine, 2006: "Using TAPs to analyse creativity in translation" in I. Kemble \& C. O'Suluivan (eds.): Proceedings of the Conference held on 12 th November 2005 in Portsmouth, Portsmouth: University of Portsmouth, 63-71.

Ibarretxe-Antuñano, Iraide, 2003: "What translation tells us about motion: a contrastive study of typologically different languages”, International Journal of English Studies 3 (2), 151-176.

IbarRetXe-Antuñano, Iraide, \& Luna Filipović, 2013: "Lexicalisation patterns and translation” in Ana Rojo López \& Iraide IbarRetXe-Antuñano (eds.): Cognitive Linguistics and Translation, Germany: Mouton de Gruyter, 251-282.

Jausovec, Norbert, 2000: "Differences in Cognitive Processes Between Gifted, Intelligent, Creative, and Average Individuals While Solving Complex Problems: An EEG Study", Intelligence 28, 213-237.

KRINGS, Hans P, 1986: Was in den Köpfen von Übersetzern vorgeht. Eine empirische Untersuchung zur Struktur des Übersetzungsprozesses bei fortgeschrittenen Französischlernern, Tübingen: Narr.

Kussmaul, Paul, 1991: "Creativity in the Translation Process: Empirical Approaches" in Kitty M. van Leuven-Zwart \& Antonius Bernardus Maria NaAIJkens (eds.): Translation Studies: the State of the Art. Proceedings of the First S. Holmes Symposium on Translation Studies, Amsterdam: Rodopi, 91-102.

Kussmaul, Paul, 2005: "Translation through visualization", Meta 50 (2), 378-391 [doi: 10.7202/010943ar].

Kussmaul, Paul, 2007: Kreatives Übersetzen. Studien zur Translation, vol. 10, Tübingen: Stauffenburg.

LeIJTen, Mariëlle, \& Luuk van WaEs, 2013: "Keystroke Logging in Writing Research: Using Inputlog to Analyze and Visualize Writing Processes", Written Communication 30 (3), 358-392 [doi: 10.1177/0741088313491692].

LeWAndowskI, Wojciech, \& Jaume Mateu, 2016: "Thinking for translating and intra-typological variation in satellite-framed languages", Review of Cognitive Linguistics 14 (1), 185-208.

Martindale, Collin, \& Nancy Hasenfus, 1978: "EEG Differences as a Function of Creativity, Stage of the Creative Process, and Effort to be Original”, Biol. Psychol. 6, 157-167.

Molés-CASES, Teresa, 2016: La traducción de los eventos de movimiento en un corpus paralelo alemán-español de literatura infantil y juvenil, Frankfurt am Main: Peter Lang. 
Molés-CASES, Teresa, 2018: "Some advances in the study of the translation of manner of motion events. Integrating key concepts of Descriptive Translation Studies and 'Thinking for Translating'”, Review of Cognitive Linguistics 16 (1), 152-190.

Muñoz Martín, Ricardo, \& José Ma Cardona Guerra, 2018: "Translating in fits and starts: pause thresholds and roles in the research of translation processes", Perspectives 27, 525-551.

Muñoz Martín, Ricardo, \& Celia Martín de León, 2018: “Fascinatin' Rhythm -and Pauses in Translators' Cognitive Processes", Hermes -Journal of Language \& Communication in Business 57, 29-47.

OAKLEY, Todd, 1996: From Attention to Meaning Explorations in Semiotics, Linguistics and Rhetoric, Berlin and New York: Peter Lang.

Perteghella, Manuela, \& Eugenia Loffredo, 2006: Translation and Creativity. Perspectives on Creative Writing and Translation Studies, London and New York: Continuum.

Rojo López, Ana María, 2017: "The Role of Creativity" in John W. Schwieter \& Aline Ferreira: The Handbook of Translation Studies and Cognition, Hoboken, NJ: Wiley, 350-368.

Rojo López, Ana María (ed.), 2019: La investigación de la creatividad en traducción: Resultados de los proyectos TRANSCREA, Granada: Comares.

Rojo López, Ana María, \& Paula Cifuentes-Férez, 2017: "On the reception of translations: Exploring the impact of typological differences on legal contexts" in Iraide IbarRetXe-Antuñano (ed.): Motion and space across languages and applications, Amsterdam: John Benjamins, 367-398.

Rosenqvist, Simon, 2015: Developing pause thresholds for keystroke logging analysis. B.A. thesis in cognitive science, University of Umeå, Sweden [http://www.diva-portal.org/smash/get/ diva2:834468/FULLTEXT01.pdf].

ŠarČević, Susan, 2000: "Creativity in legal translation: How much is too much?" in Andrew Chesterman, Natividad Gallardo San Salvador, \& Yves Gambier (eds.), Translation in Context: Selected Papers from the EST Congress, Granada 1998, Amsterdam, The Netherlands / Philadelphia, 281-229

SHaw, Melvin, 1989: "The eureka process: A structure for the creative experience in science and engineering”, Creativity Research Journal 2, 286-298.

SLoBIN, Dan I., 1991: "Learning to think for speaking. Native language, cognition, and rhetorical style”, Pragmatics 1, 7-26. 
SLoBIN, Dan I., 1996a: From 'thought and language' to 'thinking for speaking'” in John Gumperz \& Stephen C. Levinson (eds.): Rethinking Linguistic Relativity, Cambridge: Cambridge University Press, 195-217.

SLobIN, Dan I., 1996b: "Two ways to travel: verbs of motion in English and Spanish" in Masayoshi Shibatani \& Sandra A. Thompson (eds.): Grammatical constructions: Their form and meaning, Oxford: Clarendon Press, 195-220.

Slobin, Dan I., 1997: "Mind, code and text” in Joan Brbee, John Haiman, \& Sandra A. Thompson (eds.): Essays on language function and language type: Dedicated to T. Givón, Amsterdam: John Benjamins, 437-467.

SLoBIn, Dan I., 2003: "Language and Thought online: Cognitive consequence of linguistic relativity" in Dedre Gentner \& Susan Goldin-Meadow (eds.): Language in mind: Advances in the study of language and thought, Cambridge, MA: MIT Press, 157-192.

SLobIN, Dan I., 2006: "What makes Manner of motion salient? Explorations in linguistic typology, discourse and cognition" in Maya Hickman \& Stephanie Robert (eds.): Space in languages: Linguistic systems and cognitive categories, Amsterdam / Nueva York: John Benjamins, 59-82.

Strömqvist, Sven, \& Ludo Verhoeven (eds.), 2004: Relating Events in Narrative: Typological and Contextual Perspectives, New Jersey: Lawrence Erlbaum.

TALmy, Leonard, 1985: "Lexicalization patterns. Semantic structure in lexical forms" in Timothy SHopen (ed.): Language typology and lexical descriptions, vol. III, Cambridge: Cambridge University Press, 36-149.

TALmy, Leonard, 1991: "Path to realization. A typology of event conflation”, Berkeley Linguistic Society 7, 480-519.

TALmy, Leonard, 2000: Toward a Cognitive Semantics, vol. II, Cambridge, Massachuset: MIT Press.

Torrance, E. Paul, 1962: Guiding creative talent, Englewood Cliffs, NJ: Prentice Hall.

Valdés, Cristina, 2008: "Creativity in advertising translation", Quaderns de filologia. Estudis literaris 13 (Special issue on Creative Translation), 37-56.

Vartanian, Oshin, Colin Martindale, \& Jonna Kwiatkowski, 2007: "Creative potential, attention, and speed of information processing", Personality and individual differences 43, 1470-1480.

Vohs, Katheleen, Joseph P. Redden, \& Ryan Rahinel, 2013: "Physical Order Produces Healthy Choices, Generosity, and Conventionality, Whereas disorder Produces Creativity", Psychological Science 24 (9) 1860-1867. 
Wallach, Michael A., \& Nathan Kogan, 1965: Modes of thinking in young children: A study of the creativity intelligence distinction, Holt, Rinehart, \& Winston: New York.

Wallas, Graham, 1926: The Art of Thought, New York: Harcourt Brace

\section{Appendixes}

\section{Appendix 1. Text}

Whatever vague plan I had conceived regarding returning to my pond is wiped from my mind as I zigzag and dive and leap to avoid the fireballs. When there's a hiss, I act or die. A lifetime of watching the Hunger Games lets me know that certain areas of the arena are rigged for certain attacks. How long I scramble along dodging the fireballs I can't say, but the attacks finally begin to abate. I wait for the next hiss, the next signal to bolt. It doesn't come. My hand fumbles to my braid and finds a fireball has seared off at least six inches of it. Strands of blackened hair crumble in my fingers. I stare at them, fascinated by the transformation, when the hissing registers. The fireball crashes into the ground at my side, but not before it skids across my right calf. Seeing my pants leg on fire sends me over the edge. I twist and scuttle backward on my hands and feet, shrieking, trying to remove myself from the horror.

\section{Appendix 2. CREA test}

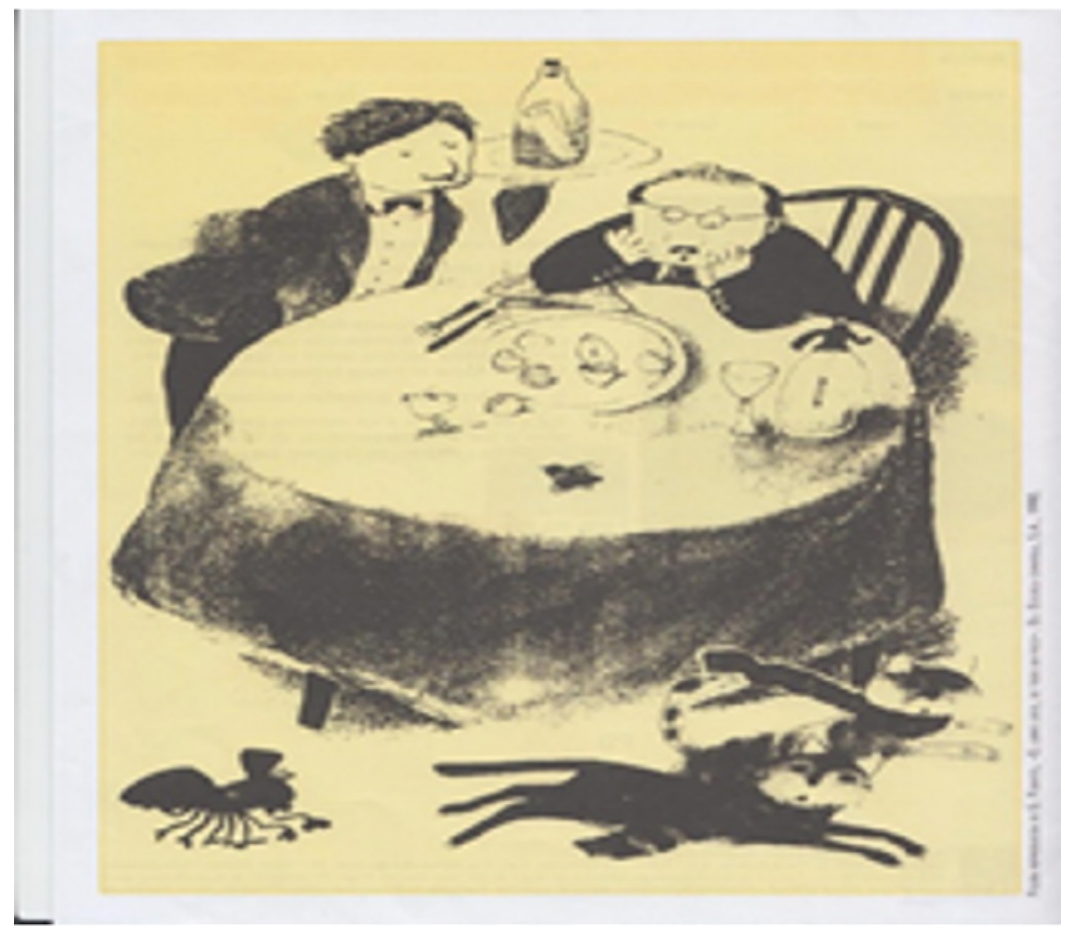




\section{Appendix 3. Marking sheet}

\begin{tabular}{|c|c|c|c|c|c|c|}
\hline \multicolumn{7}{|c|}{ ACCURACY (-) } \\
\hline FACTOR & \multicolumn{2}{|l|}{ MEANING } & \multicolumn{2}{|c|}{ PRAGMATIC FUNCTION* } & \multicolumn{2}{|c|}{ CORRECTNESS } \\
\hline \multirow[t]{3}{*}{ Type of error } & False meaning & $-0,5$ & $\begin{array}{l}\text { Loss of cultural } \\
\text { reference/implied } \\
\text { meaning }\end{array}$ & -1 & Grammar errors & -1 \\
\hline & Opposite meaning & -1 & $\begin{array}{l}\text { Loss of pragmatic } \\
\text { function (humor/ } \\
\text { irony) } \\
\text { Loss of literary } \\
\text { value (metaphor, } \\
\text { alliteration, } \\
\text { anaphora...) }\end{array}$ & -1 & $\begin{array}{l}\text { Orthotypographic } \\
\text { (typos, accents, } \\
\text { punctuation, } \\
\text { spelling mistakes) }\end{array}$ & $-0,25$ \\
\hline & $\begin{array}{l}\text { Unnecessary } \\
\text { omission/addition } \\
\text { of meaning }\end{array}$ & $-0,5$ & & & & \\
\hline
\end{tabular}

\begin{tabular}{|c|c|c|c|c|}
\hline \multicolumn{5}{|c|}{ CREATIVITY (+) } \\
\hline \multirow[t]{5}{*}{ FACTOR } & FLEXIBILITI & & NOVELTY & \\
\hline & & & Unique solutions & +2 \\
\hline & Primary shifts & +1 & Solutions found in less than $10 \%$ of participants & +1 \\
\hline & Secondary shifts & +1 & Solutions found in less than $50 \%$ of participants & $+0,5$ \\
\hline & & & Solutions found in more than $50 \%$ of participants & 0 \\
\hline
\end{tabular}

